\title{
Reproductive qualities of meat chickens of the parent flock when using automatic nests
}

\author{
Elena Pilyukshina ${ }^{1, *}$, Vladimir Khaustov ${ }^{1}$, Alexander Ozhimkov ${ }^{2}$, Valentina Rusanova ${ }^{1}$, and \\ Alexey Popelyaev ${ }^{1}$ \\ ${ }^{1}$ Altai State Agricultural University, Krasnoarmejskij ave., 98, 656049 Barnaul, Russia \\ ${ }^{2}$ Separate subdivision "Novosafonovskaya poultry farm" of Kuzbass Broiler LLC, Molodezhnaya st., \\ 2a, Novosafonovskiy settlement, Prokopyevskiy district, 653224 Kemerovo region, Russia
}

\begin{abstract}
The aim of the study presented in this paper was to compare the reproductive qualities of laying hens of the parent flock of the ROSS 308 cross when using manual and automatic egg collection. The experimental part was carried out in the production conditions of a separate subdivision "Novosafonovskaya poultry farm" of Kuzbass Broiler LLC on laying hens of the parent flock of the ROSS 308 cross at the age of 155-435 days. The use of automatic nests for collecting hatching eggs did not affect the intensity of egg production, but contributed to an increase in the yield of hatching eggs due to a decrease in the culled eggs because of egg contamination, breakage, cracked shell and others. A decrease in the number of cleaned eggs among the hatching eggs contributed to an increase in the hatching of chicks and, as a consequence, an increase in the yield of day old chicks per initial layer by 11.9 heads or $8.5 \%$.
\end{abstract}

\section{Introduction}

Poultry farming is a knowledge-intensive and dynamically developing branch of animal husbandry both in Russia and in the world. At the same time, this industry is the leading one in providing the population with a high-value and dietary product - broiler chicken meat [1-9]. An important link in the technological chain of meat production of broiler chickens is considered to be the parent flock, the keeping of which is constantly being improved, including on the basis of innovative equipment [10-16].

The main task of the parent flock is the production of hatching eggs. Any reasons that reduce its quantity lead to an increase in the cost of day-old chicks. Therefore, the search for effective means eliminating or reducing the influence of these causes is an urgent task facing scientists and farm specialists.

Methods for increasing the yield of hatching eggs are the cleanliness of the eggs, the collection timeliness and the accuracy during transportation. With manual collection, this largely depends on the person, his responsibility and attitude to work.

Therefore, the aim of the study was to compare the reproductive qualities of laying hens of the parent flock of the ROSS 308 cross when using manual and automatic collection of eggs.

*Corresponding author: lexx-74@bk.ru 


\section{Materials and Methods}

The studies were carried out in the production conditions of a separate subdivision "Novosafonovskaya poultry farm" of Kuzbass Broiler LLC on laying hens of the parent flock of the ROSS 308 cross.

Table 1. Scheme of the experiment

\begin{tabular}{|l|l|}
\hline \multicolumn{1}{|c|}{ Group } & \multicolumn{1}{c|}{$\begin{array}{c}\text { Egg collection } \\
\text { system }\end{array}$} \\
\hline control & manual collection \\
\hline experimental & automatic nests \\
\hline
\end{tabular}

From the scheme of the experiment (Table 1), it can be seen that the birds in the control group were kept in poultry houses, where the eggs were collected manually (Fig. 1). For hens in the experimental group, automatic nests were installed (Fig. 2), which made it possible to collect eggs using a belt conveyor (Fig. 3). The duration of the experiment was 280 days from 155 to 435 days of age of hens of the parent flock.

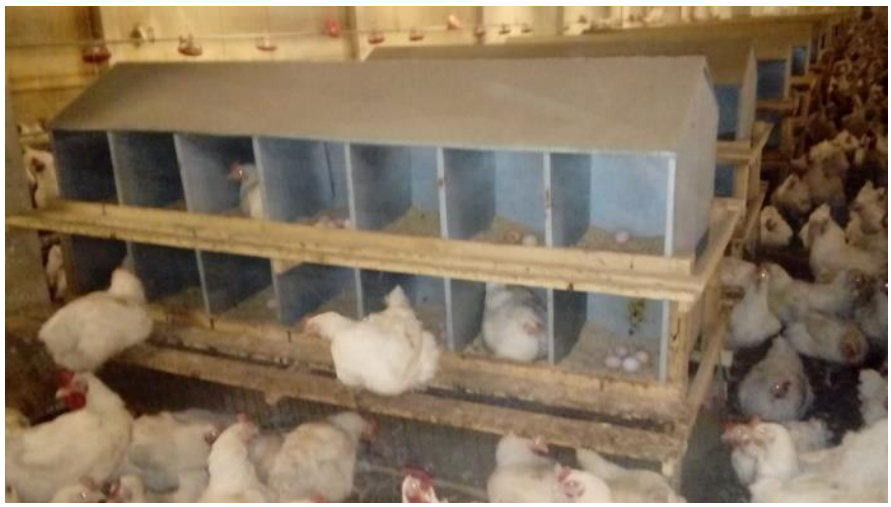

Fig. 1. Nests with manual collection of eggs

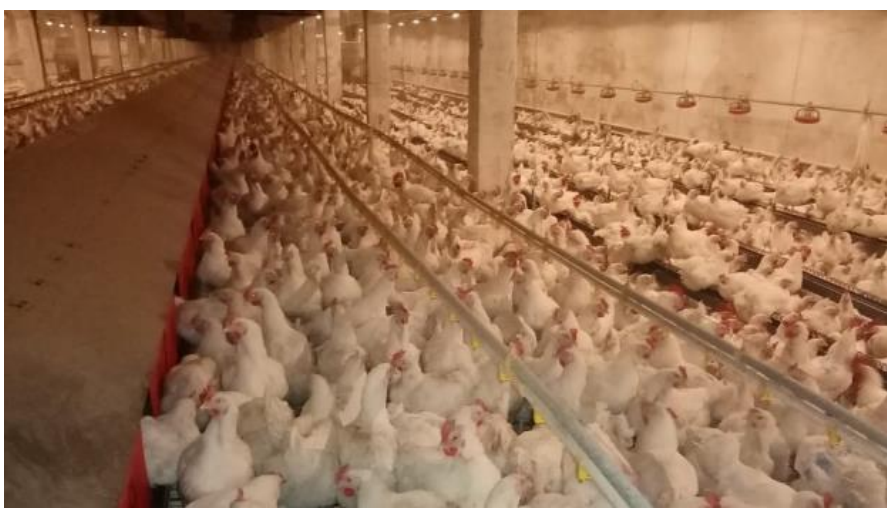

Fig. 2. Nests with automatic egg collection 


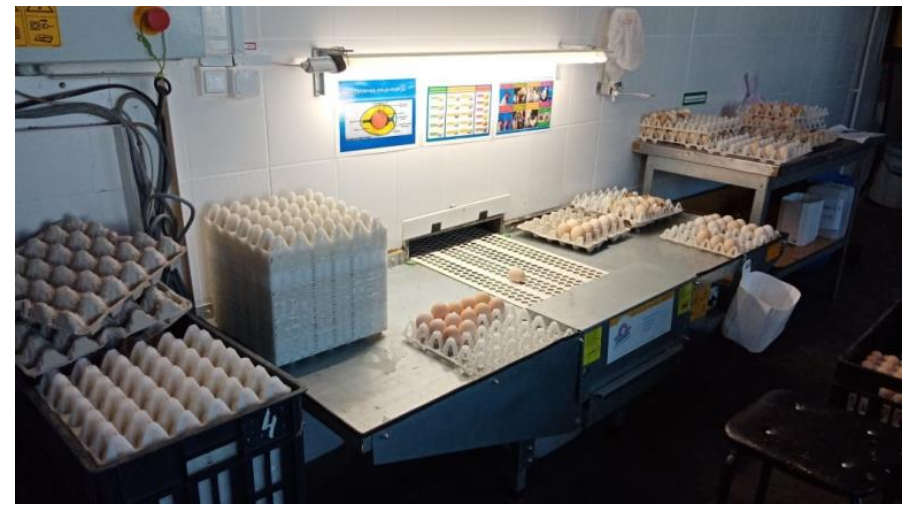

Fig. 3. Band conveyer

All other housing and feeding systems were the same and complied with the recommendations for the management of the parent flock of the ROSS 308 cross.

Accounting for egg production, as well as the results of incubation was carried out daily separately for each group. Based on these data, the following indicators were calculated: egg production rate, hatching egg yield, chick hatching and the number of chicks per initial hen.

\section{Results and Discussion}

One of the most important indicators characterizing the reproductive qualities of layers is the intensity of egg production (Fig. 4).

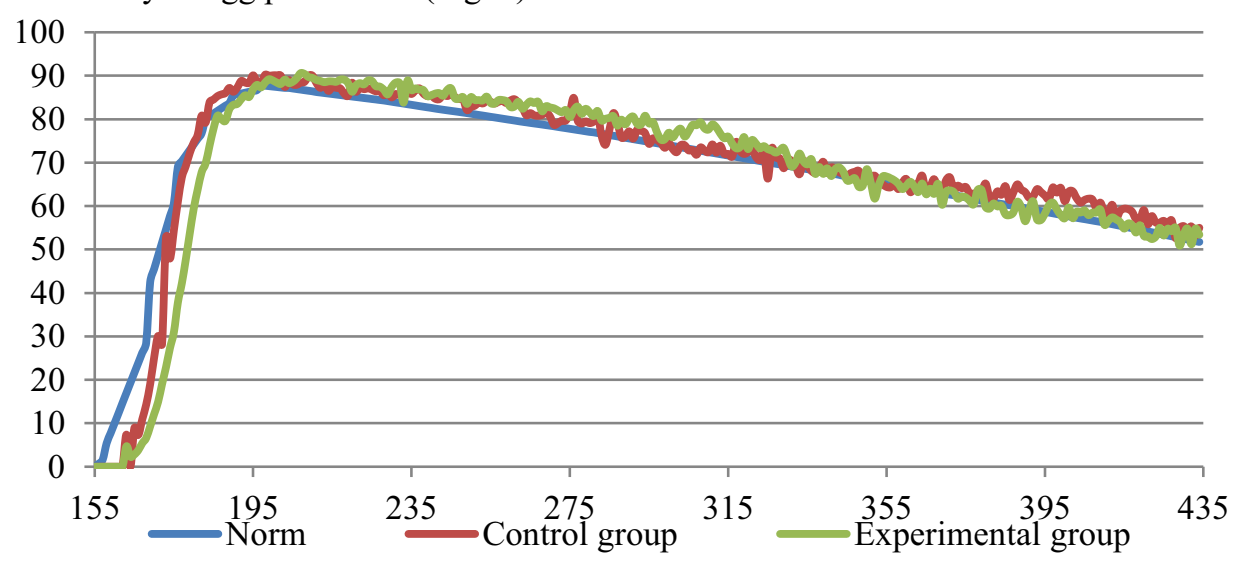

Fig. 4. Egg production intensity, \%

Analyzing the data presented in Figure 4, we came to the conclusion that the use of automatic nests had almost no effect on the intensity of egg production. The difference between the control and experimental group was not significant and did not exceed $6.8 \%$. On average, during the period of the experiment, the intensity of egg production in the experimental groups was within $68.2-69.3 \%$.

The use of automatic nests had a significant effect on hatching egg yield (Figure 5). 


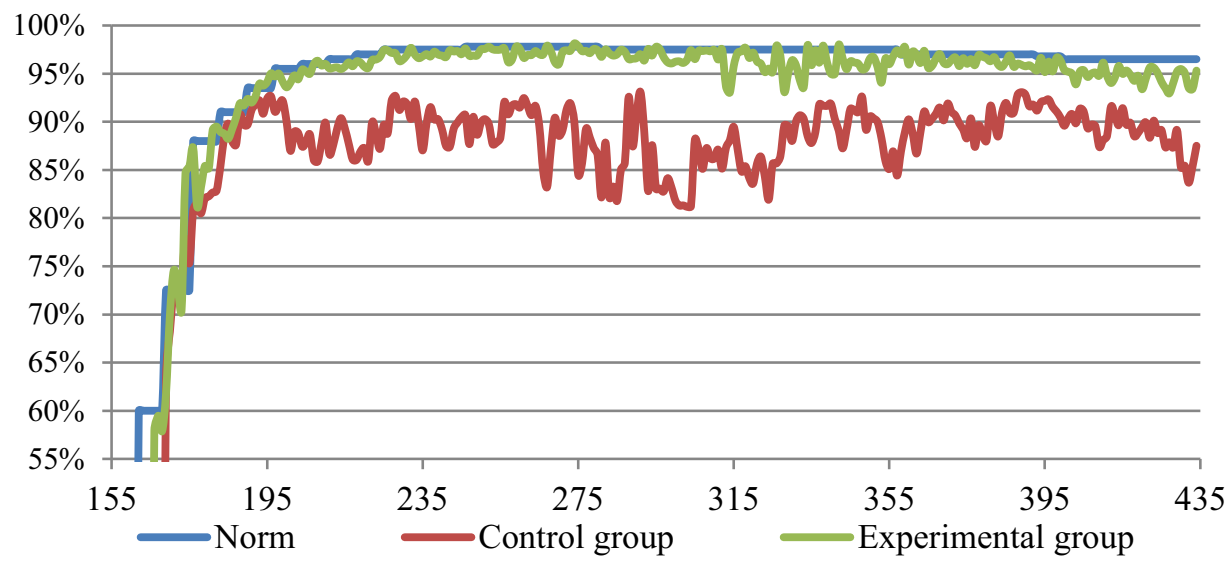

Fig. 5. Hatching egg yield, $\%$

Figure 5 shows that the hatching egg yield during automatic collection of eggs significantly exceeded this indicator with manual collection. The excess of the experimental group over the control group ranged from $0.8 \%$ to $16.2 \%$.

For a more detailed analysis of the quality of the released eggs, see Table 2.

Table 2. Egg release structure, \%

\begin{tabular}{|c|c|c|c|}
\hline Indicator & Norm & Control group & Experimental group \\
\hline Hatching egg & 95.54 & 86.45 & 93.66 \\
\hline $\begin{array}{c}\text { including } \\
\text { cleaned }\end{array}$ & 0 & 14.38 & 3.62 \\
\hline Culled egg & 4.46 & 13.55 & 6.34 \\
\hline $\begin{array}{c}\text { including } \\
\text { dirty }\end{array}$ & 0 & 6.55 & 1.02 \\
\hline breakage & 0.70 & 2.63 & 2.10 \\
\hline cracked shell & 0.80 & 0.74 & 0.31 \\
\hline other & 2.96 & 3.63 & 2.91 \\
\hline
\end{tabular}

The data in Table 2 indicate that the hatching egg yield in the experimental group was $93.66 \%$, which is slightly less than the norm $(95.65 \%)$, the difference was only $1.88 \%$. The control group on this indicator was inferior to the experimental one by $7.21 \%$, and the recommended one for the ROSS 308 cross - by $9.09 \%$.

In order to reduce the loss of hatching eggs at the poultry farm, it is customary to clean out some of the eggs. The use of automatic nests made it possible to reduce the number of cleaned eggs by 4.0 times, which affected the hatchability of chicks (Fig. 6).

In the experimental group, where automatic nests were used for collecting eggs, in comparison with the control one, the number of culled eggs decreased by 2.1 times, and it was $6.34 \%$ versus $13.55 \%$.

The decrease in culled eggs occurred due to the fact that there were 6.4 times less dirty eggs, 1.3 times less broken eggs, 2.4 times less eggs with a cracked shell, and 1.2 times less eggs rejected for other reasons. 


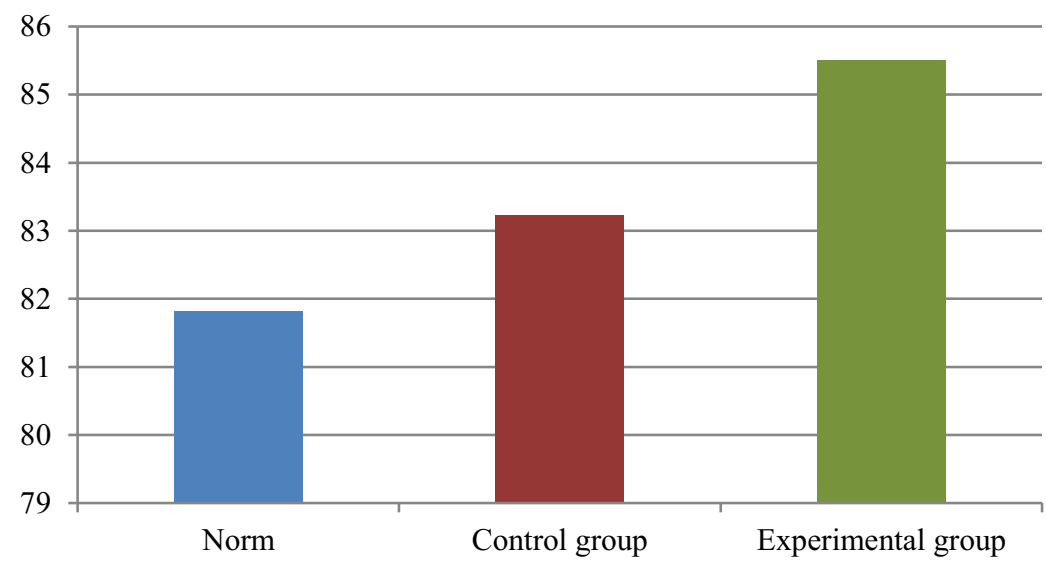

Fig. 6. Chick hatching, $\%$

The analysis of Figure 3 showed that at the poultry farm, the hatching of chicks exceeds the normative indicator for the parent flock of the ROSS 308 cross by $1.42-3.69 \%$. The use of automatic nests for collecting hatching eggs, where chick hatching was $85.50 \%$, contributed to an increase in chick hatching by $2.27 \%$ compared with manual collection of eggs.

An objective key indicator characterizing the reproductive qualities of the parent flock is the number of day-old chicks per initial hen (Fig. 7).

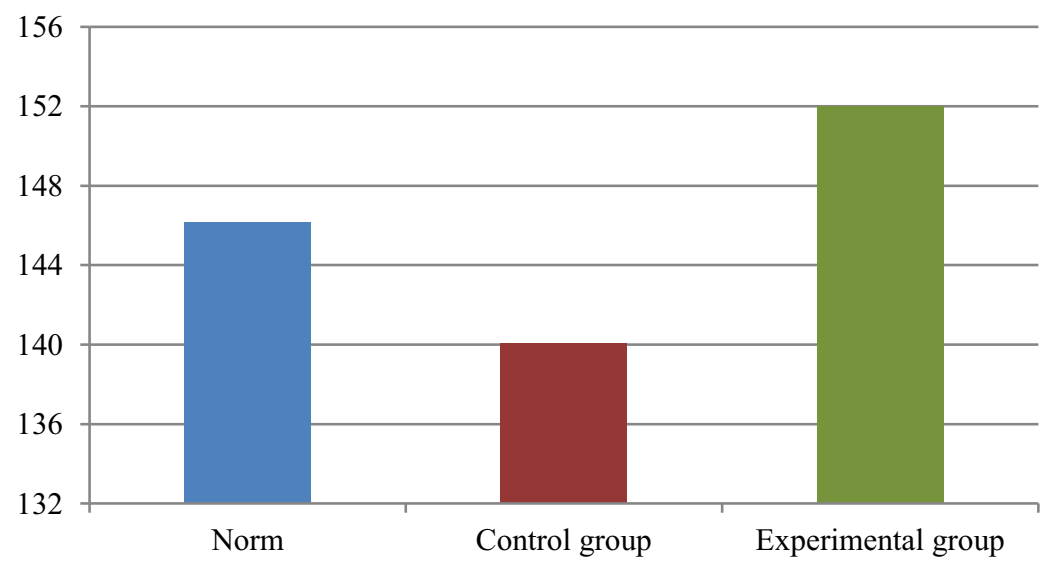

Fig. 7. Day-old chicks per initial layer, heads

Figure 4 shows that the number of day-old chicks per initial layer in the experimental group was 152.0 heads, which is 5.8 heads more or $4.0 \%$ compared to the norm, and by 11.9 heads or $8.5 \%$ compared with the control group.

\section{Conclusions}

Thus, the use of automatic nests for collecting hatching eggs did not affect the egg production of the bird. But it contributed to an increase in the yield of hatching eggs by $7.21 \%$ due to a decrease in the culled eggs by 2.1 times, including due to contamination, breaking, cracked shells and others by 6.4 times, 1.3 times, 2.4 times and 1.2 times, 
respectively. A decrease in the number of cleaned eggs among the hatching eggs (by 4.0 times) contributed to an increase in the hatching of chicks by $2.27 \%$ and, as a consequence, to an increase in the yield of day-old chicks per initial layer by 11.9 heads or $8.5 \%$.

\section{Acknowledgements}

We express our gratitude to the management and employees of the Separate Subdivision "Novosafonovskaya Poultry Farm" of Kuzbass Broiler LLC for effective cooperation.

\section{References}

1. V.I. Fisinin, Animal husbandry of Russia, 6, 2 (2013)

2. V.I. Fisinin, Poultry in Russia - an innovative development strategy, 148 (2009)

3. V. Fisinin, Animal husbandry of Russia, 3, 2 (2014)

4. G.A. Bobyleva, Poultry and poultry products, 1, 8 (2015)

5. G.A. Bobyleva, Meat technologies, 5, 43 (2011)

6. G.A. Bobylev, V.V. Gushchin, Poultry and poultry products, 1, 4 (2020)

7. A.B. Kornienko, E.E. Mozhaev, A.E. Mozhaev, Animal husbandry, 7, 2 (2015)

8. E. Chirkov, N. Denin, Agribusiness: Economics, management, 2, 30 (2001)

9. A.I. Altukhov, Agrarian Russia, 2, 2 (2008)

10. A.V. Buyarov, V.S. Buyarov, Vestnik of the Altai State Agrarian University, 6, 165 (2015)

11. B.C. Buyarov, E.A. Buyarova, V.A. Borodin, Animal husbandry, 9, 24 (2003)

12. Sabine G. Gebhardt-Henrich, Michael J.Toscano, Hanno Würbel, Applied Animal Behaviour Science, 203, 24 (2018)

13. Muhammad Shabir Shaheen, Shahid Mehmood, Athar Mahmud, Amjad Riaz, Poultry Science, 99 (7), 3501 (2020)

14. N.B. Saginbaeva, Zh.M. Bektursyn, Innovations in science and practice: materials of the III international scientific and practical conference, 130 (2017)

15. N. Leksrisompong, H. Romero-Sanchez, E.O. Oviedo-Rondón, J. Brake, Poultry Science, 93 (5, 1), 1045 (2014)

16. V.N. Khaustov, E.V. Pilyukshina, A.N. Konovalov, Vestnik of the Altai State Agrarian University, 9 (191), 94 (2020) 